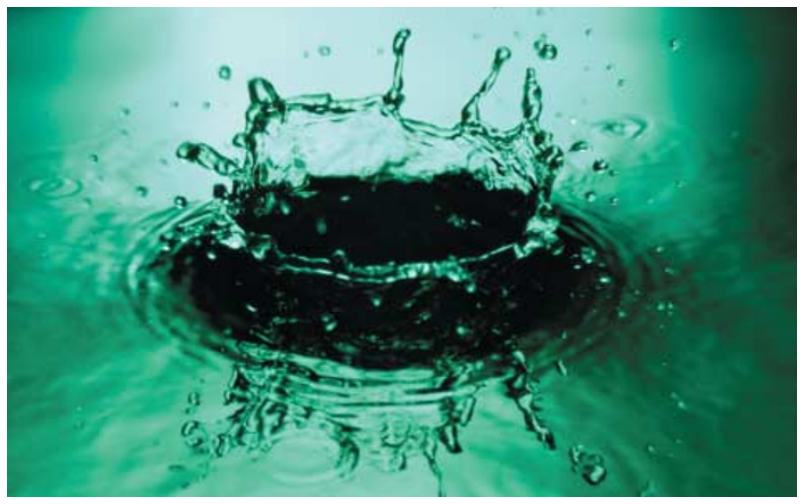

ION CHANNELS

\section{Thirsty work}

That sodium has a crucial role in body-fluid control has been known for many years, but how the brain controls behaviours that regulate water and sodium intake, and sodium's involvement in this process, are not fully understood. Now, research published in The Journal of Neuroscience has shed new light on salt-intake behaviour in mice.

The $\mathrm{Na}_{\mathrm{x}}$ channel is already known to be involved in salt intake, and Hiyama et al. compared the salt-intake behaviour of $\mathrm{Na}_{x}-$ knockout and wild-type mice in a series of experiments.In each, all mice were provided with both distilled water and a $0.3 \mathrm{M} \mathrm{NaCl}$ solution to drink, and, while fully satiated with water, showed no marked preference for either. After 48 hours dehydration, wildtype mice were more sensitive to saline, and showed a strong preference for the distilled water. However, mutant mice did not show this increased sensitivity and continued to ingest similar amounts of saline solution and distilled water. As there is already evidence that $\mathrm{Na}_{x}$ is not involved in tasting, the researchers proposed that the abnormal salt intake seen in dehydrated $\mathrm{Na}_{\mathrm{x}}$-knockout mice is the result of brain defects.

Hiyama et al. then investigated the drinking behaviour of the mice during microinjection of different $\mathrm{NaCl}$ concentrations into the cerebral ventricle. Infusion of an isotonic solution $(0.145 \mathrm{M} \mathrm{NaCl})$ did not result in differences in behaviour between the wild-type and mutant mice, with both taking equivalent volumes of water and $0.3 \mathrm{M} \mathrm{NaCl}$. However, when a hypertonic solution $(0.5 \mathrm{M} \mathrm{NaCl})$ was infused, wild-type mice showed a strong aversion to the saline solution, but mutant mice did not.

The expression of $\mathrm{Na}_{\mathrm{x}}$ is limited to a few regions of the CNS, including the subfornical organ (SFO), a circumventricular organ that is located in the forebrain. The authors showed that normal salt-intake behaviour could be rescued if the SFO was transfected with a $\mathrm{Na}_{\mathrm{x}}$-expressing viral vector, indicating both that the SFO regulates salt-intake behaviour and that the $\mathrm{Na}_{x}$ channel is the sensor that allows it to do so.

Sarah Archibald

\section{(2) References and links}

original Reference PAPeR Hiyama, T. Y., Watanabe, E., Okado, H. \& Noda, M. The subfornical organ is the primary locus of sodium-level sensing by $\mathrm{Na}_{x}$ sodium channels for the control of salt-intake behavior. J. Neurosci. 24, 9276-9281 (2004) FURTHER READING Amiry-Moghaddam, M. \& Ottersen, O. P. The molecular basis of water transport in the brain. Nature Rev. Neurosci. 4, 991-1001 (2003)

\title{
DEVELOPMENT
}

\section{Having the NRG to migrate}

Most of the inhibitory interneurons of the cerebral cortex originate in the medial ganglionic eminence (MGE), one of the subdivisions of the subcortical telencephalon. From the MGE, they migrate tangentially (parallel to the brain surface) to colonize the cortex. The migrating cells are thought to be kept on track by a combination of repulsive and attractive cues, but until recently, only chemorepellants had been described. Now, in a study reported in Neuron, Flames and colleagues identify Neuregulin-1 (NRG1) as the first candidate for the chemoattractant role.

There are three main isoforms of NRG1: Types I and II (collectively known as NRG1-Ig), which are secreted, and Type III (also known as NRG1-CRD), which is membranebound. Flames et al. showed that Nrg1-CRD mRNA is expressed in a 'corridor' through the lateral ganglionic eminence that corresponds to the migration pathway of cortical interneurons. When faced with the choice of migrating on $\mathrm{Nrgl}$ $C R D$-expressing or -non-expressing cells, MGE cells were around twice as likely to choose the Nrg1-CRDexpressing cells, and the authors propose that NRG1-CRD provides a permissive substrate for interneuron migration.

The expression pattern of NRG1Ig is consistent with the idea that it functions as a diffusible chemoattractant. At the developmental stage when interneurons first begin to enter the cortex, $\mathrm{Nrg1-Ig}$ is expressed at higher levels in more lateral cortical regions, but its expression spreads medially as development proceeds, mirroring the advancing front of migrating interneurons. Flames et al. showed that MGE cells were attracted towards a source of NRG1-Ig in culture, and in brain slices, a graft of NRG1-Ig-expressing cells in the ventrolateral telencephalon could attract MGE cells and divert them from their usual migration course.
The NRG1 receptor ERBB4 is expressed in a subpopulation of MGE-derived cells, and the authors asked whether the attractive effects of NRG1 are mediated through this receptor. They found that expression of a dominant negative form of ERBB4 ( $d n E r b B 4)$ in cultured MGE cells rendered these cells almost completely unresponsive to the attractive effects of a cortical tissue explant. In brain slices, $d n E r b B 4$-expressing MGE cells accumulated in the basal telencephalon instead of migrating to the cortex. Also, knockout mice that lacked either ErbB4 or Nrg1 showed decreased numbers of inhibitory interneurons in the cortex.

Flames et al. conclude that different isoforms of NRG1 act at short and long range to guide MGEderived interneurons towards the cortex, and that this chemoattraction is mediated by ERBB4. However, as not all MGE-derived cells express ERBB4, it is probable that more chemoattractants for cortical interneurons are waiting to be discovered.

Heather Wood

(2) References and links ORIGINAL RESEARCH PAPER Flames, N. et al. Short- and long-range attraction of cortical GABAergic interneurons by Neuregulin-1. Neuron 44, 251-261 (2004)

FURTHER READING Marín, O. \& Rubenstein, J. L. R. A long, remarkable journey: tangential migration in the telencephalon. Nature Rev. Neurosci. 2, 780-790 (2001)

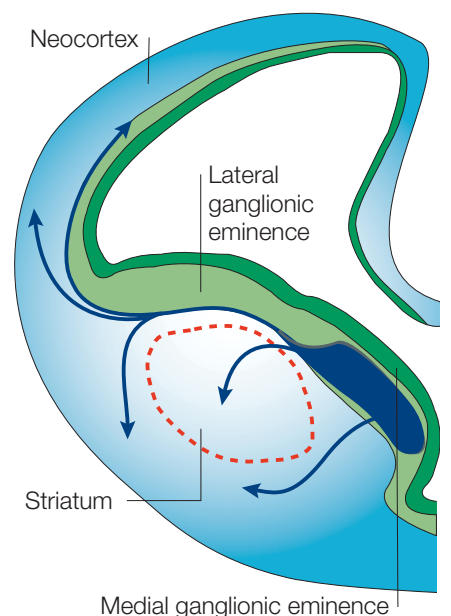

Schematic diagram of the embryonic day 13.5 mouse brain, showing routes of migration for cells derived from the medial ganglionic eminence. 